Masaaki Saito* • Hiroto Matsumine* • Hajime Tanaka

Atsushi Ishikawa $\cdot$ Satoe Shimoda-Matsubayashi

Alejandro A. Schäffer • Yoshikuni Mizuno • Shoji Tsuji

\title{
Refinement of the gene locus for autosomal recessive juvenile parkinsonism (AR-JP) on chromosome 6q25.2-27 and identification of markers exhibiting linkage disequilibrium
}

Received: October 22, 1997 / Accepted: December 5, 1997

\begin{abstract}
Autosomal recessive juvenile parkinsonism (ARJP) (MIM 600116) is a hereditary neurodegenerative disorder characterized by levodopa-responsive parkinsonism with a mean age at onset of 23.2 years. We recently mapped the AR-JP gene locus to a 17-cM interval on chromosome 6q25.2-27. To further narrow the candidate region of the AR-JP gene, we performed detailed linkage analysis using densely placed genetic markers in this region (D6S437, D6S1581, D6S1579, D6S305, D6S411, SOD2, D6S253, D6S1599, D6S1719 and D6S264). Pairwise linkage analysis revealed the highest cumulative maximal lod score of 9.13 at D6S1579 $(\theta=0.05)$, and multipoint linkage analysis revealed the highest cumulative lod score of 12.4 at the locus $3 \mathrm{cM}$ telomeric to D6S1599. Observation of obligate recombination events narrowed the candidate region to a 13-cM region between D6S1579 and D6S264. Furthermore, we identified two marker loci, D6S1579 and D6S1599, which exhibit strong linkage disequilibrium with the AR-JP locus: $\chi^{2}(2 \times n$ table $)=84.22 ; P<0.0001, \chi^{2}$ [likelihoodratio test $($ LRT $)]=20.66 ; P<0.0001, \lambda=0.40$ and $\chi^{2}$ $(2 \times n$ table $)=63.37 ; P<0.0001, \chi^{2}($ LRT $)=10.32 ; P<$ $0.0001, \lambda=0.30$, respectively. These results suggest that the candidate region for the AR-JP gene is most likely located near the 4-cM region encompassing D6S1579 and D6S1599.
\end{abstract}

M. Saito $\cdot$ H. Tanaka $\cdot$ S. Tsuji $(\square)$

Department of Neurology, Brain Research Institute, Niigata

University, 1-757 Asahimachi-dori, Niigata 951, Japan

Tel. +81-25-223-6161 ext. 5183; Fax +81-25-223-3620

e-mail: tsuji@cc.niigata-u.ac.jp

H. Matsumine $\cdot$ S. Shimoda-Matsubayashi $\cdot$ Y. Mizuno

Department of Neurology, Juntendo University School of Medicine,

Tokyo, Japan

A. Ishikawa

Department of Neurology, Nishiojiya National Hospital, Niigata, Japan

A. A. Schäffer

National Human Genome Research Institute, National Institutes of Health Bethesda, MD, USA

* These authors contributed equally to this work.
Key words Autosomal recessive juvenile parkinsonism (AR-JP) · Parkinson's disease (PD) · Chromosome 6q25.2$27 \cdot$ Linkage disequilibrium

\section{Introduction}

Autosomal recessive juvenile parkinsonism (AR-JP) (MIM 600116) is a hereditary neurodegenerative disorder characterized by levodopa-responsive parkinsonism with a mean age at onset of 23.2 years and a slowly progressive course (Ishikawa and Tsuji 1996). The clinical features of AR-JP are characterized by mild parkinsonism including tremor, rigidity, bradykinesia and postural instability, with a good response to levodopa. In addition, diurnal fluctuation of parkinsonian symptoms, dystonic posture in the foot, frequent occurrence of the wearing-off phenomenon, dopa-induced dyskinesia and alleviation of the severity of parkinsonian symptoms following sleep are also characteristic of AR-JP (Ishikawa and Tsuji 1996).

Families with this condition have been described predominantly in the Japanese population, and the condition has occasionally been given different names, including an autosomal recessive early-onset parkinsonism with diurnal fluctuation (AR-EPDF) or a familial form of juvenile parkinsonism (Yamamura et al. 1973; Kondo et al. 1990; Mizutani et al. 1993; Takubo et al. 1996). Thus, there are considerable similarities in the clinical features of AR-JP with those of Parkinson's disease (PD), one of the most common neurodegenerative disorders, affecting more than $1 \%$ of the population over 55 years of age (de Rijk et al. 1995). Identification of the causative gene for AR-JP by means of positional cloning, therefore, would not only help elucidate the molecular mechanisms of selective degeneration of dopaminergic neurons in the substantia nigra in AR-JP but also bring insight into the mechanisms of degeneration of these neurons in PD.

With this background, we performed a detailed linkage study on the 13 Japanese AR-JP families and recently mapped the gene for AR-JP to a 17-cM region on chromo- 
some 6q25.2-27 (Matsumine et al. 1997). To narrow the candidate region, we further extended our linkage analysis of AR-JP using additional densely spaced markers in this region and identified markers which are in strong linkage disequilibrium with the AR-JP locus.

\section{Materials and methods}

\section{AR-JP families}

Following receipt of their informed consent, 14 multigenerational Japanese AR-JP families were examined by neurologists (Fig. 1). Genomic DNAs were obtained from peripheral blood leukocytes of 62 individuals: 23 individuals with AR-JP and 39 unaffected individuals. This study involved a recently identified AR-JP family (family 455) in addition to the 13 families for which we performed linkage analysis in our previous study (Matsumine et al. 1997). Family 105 originated from Aomori Prefecture. Although the other 13 families originated from Niigata Prefecture, they were not related so far as we could determine. Clinical or neuropathological findings on the 13 families, except for family 455 , have been described previously (Yamamura et al. 1973; Tanaka et al. 1987; Mizutani et al. 1993; Takahashi et al. 1994; Saito et al. 1995; Ishikawa and Tsuji 1996; Takubo et al. 1996; Matsumine et al. 1997). Neuropathological findings were obtained in families 101 and 556, which demonstrated neuronal loss and gliosis in the medial and ventrolateral regions of the substantia nigra pars compacta. Lewy bodies were not observed in substantia nigra. Neuronal cell loss and a low melanin content of the locus ceruleus were also observed (Mizutani et al. 1993; Takahashi et al. 1994; Takubo et al. 1996). In 11 of the 14 families (families 105, 547, 548, 549, 550, 551, 553, 554, 555,556 and 557), the parents of affected individuals were consanguineous. In family 552, parents III- 1 and III- 2 of the affected individuals IV-2, IV-5 and IV-8 were distant relatives, although their exact relationship could not be determined. Affected individuals were observed in only one generation in all the families.

The mean ages at onset are $24.6 \pm 3.2$ (mean \pm SEM, range $8-38, n=9$ ) years for male patients, $22.5 \pm 2.7$ (mean \pm SEM, range $8-43, n=17$ ) years for female patients and $23.2 \pm 2.1$ (mean \pm SEM, range $8-43, n=26$ ) years for male and female patients.

\section{Linkage analysis}

High-molecular-weight genomic DNAs were extracted from peripheral blood leukocytes by standard procedures (Sambrook et al. 1989) as well as from formalin-fixed or paraffin-embedded brain tissues as previously described (Goelz et al. 1985). The microsatellite markers used in the present study are D6S437 (Gyapay et al. 1994), D6S1581 (Dib et al. 1996), D6S1579 (Dib et al. 1996), D6S305 (Gyapay et al. 1994), D6S411 (Gyapay et al. 1994), SOD2
(Matsumine et al. 1997), D6S253 (Volz et al. 1994), D6S1599 (Dib et al. 1996), D6S1719 (Dib et al. 1996) and D6S264 (Gyapay et al. 1994), of which D6S437, D6S305, D6S411, SOD2, D6S253, and D6S264 were used in our previous study (Matsumine et al. 1997). The consensus genetic maps of these markers are shown in Fig. 2 (Gyapay et al. 1994; Volz et al. 1994; Dib et al. 1996). Genetic distances were estimated using Haldane's map function. Individuals were genotyped using these microsatellite markers (Weber and May 1989).

The gene frequency for AR-JP was assumed to be 0.003 (Tanaka et al. 1987; Matsumine et al. 1997). The genetic model assumed an autosomal recessive mode of inheritance of AR-JP with age-dependent penetrance. Five ageassociated risk classes (I: 0-9 years old, 0.076; II: 10-21 years old, 0.374; III: 22-33 years old, 0.678; IV: 34-44 years old, 0.891; and V: 45 years and over, 1.000) were identified from the cumulative age at the onset of the AR-JP curve of the 14 families. Calculations were based on equal recombination rates in males and females. Samples from control subjects who were not related to the families or to each other, consisting of at least 53 Japanese mainly originating from Niigata, were analyzed in order to determine allele frequencies for these markers. Individuals were examined by neurologists and judged to be affected or unaffected with AR-JP based on the results of the neurological examination. The phenotypes of those who did not undergo neurological examination were considered to be unknown for the calculation of lod scores.

Calculation of lod scores was performed using the MLINK and LINKMAP subprograms of the LINKAGE computer program package version 5.1 (Lathrop and Lalouel 1985; Lathrop et al. 1985) and the FASTLINK package version 3.0P (Cottingham et al. 1993; Schäffer et al. 1994). Some of the long runs were carried out using FASTLINK in parallel (Gupta et al. 1995) on top of the TreadMarks distributed shared memory system (Amza et al. 1996) on an IBM SP2 computer at the National Institutes of Health. Multipoint calculations by homozygosity mapping were performed with MAPMAKER/HOMOZ (Kruglyak et al. 1995). To reduce the computation time, the allele numbers were reduced.

\section{Linkage disequilibrium analysis}

One chromosome carrying and one not carrying the AR-JP gene were identified by haplotype segregation analysis for each family (Fig. 1). For families in which consanguineous marriages had occurred, a founder chromosome was identified and used for linkage disequilibrium analysis. For families in which nonconsanguineous marriages had occurred, or for individuals with consanguineous parents where the marker loci were heterozygous and thus not identical by descent, both marker alleles were used. To test for the presence of linkage disequilibrium, an assessment of allelic association was performed by comparing allele frequencies in the AR-JP chromosomes with those obtained for at least 53 unrelated Japanese controls. Multipoint linkage 


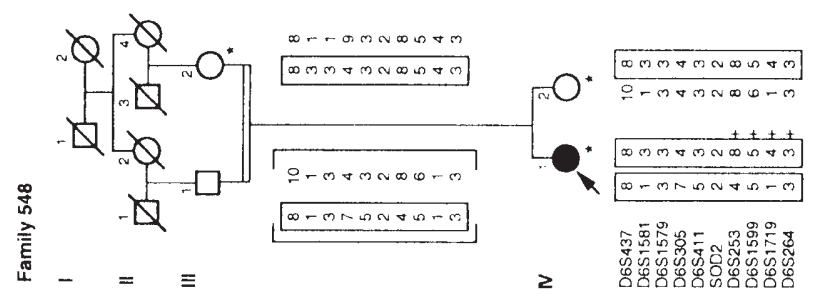

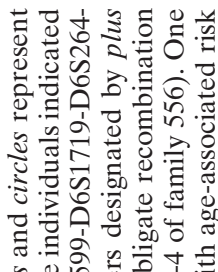

औ

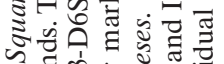

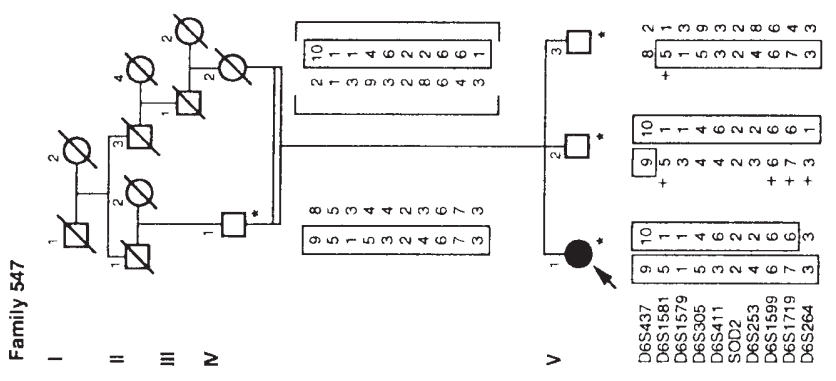

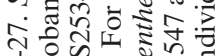

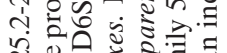

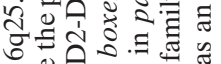

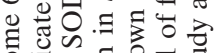

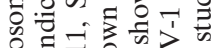

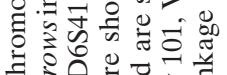

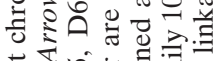

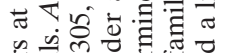

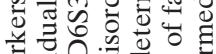

t) 9 \% क

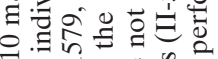

0 च

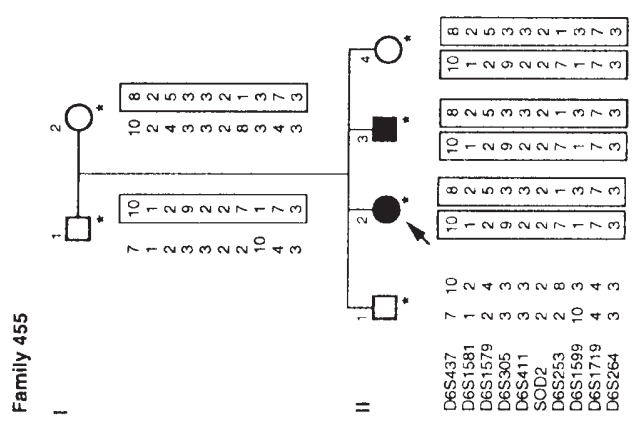

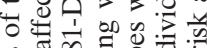

b o 0 .

踏

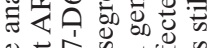

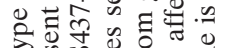

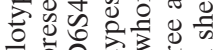

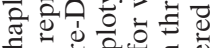

च

क

可氙

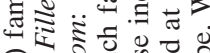

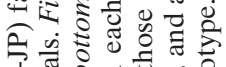

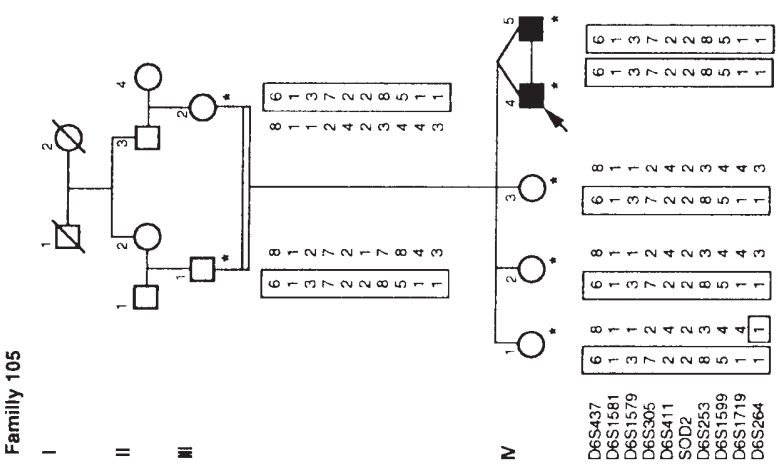

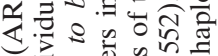

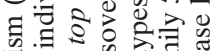

긍 :

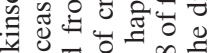

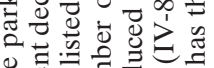

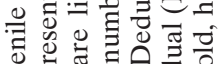

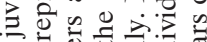

记

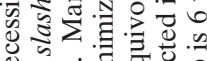

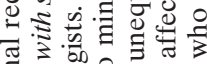

च.

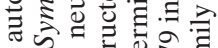

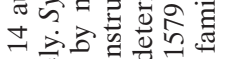

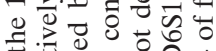

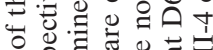

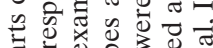

당

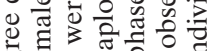

战可

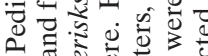

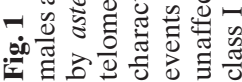



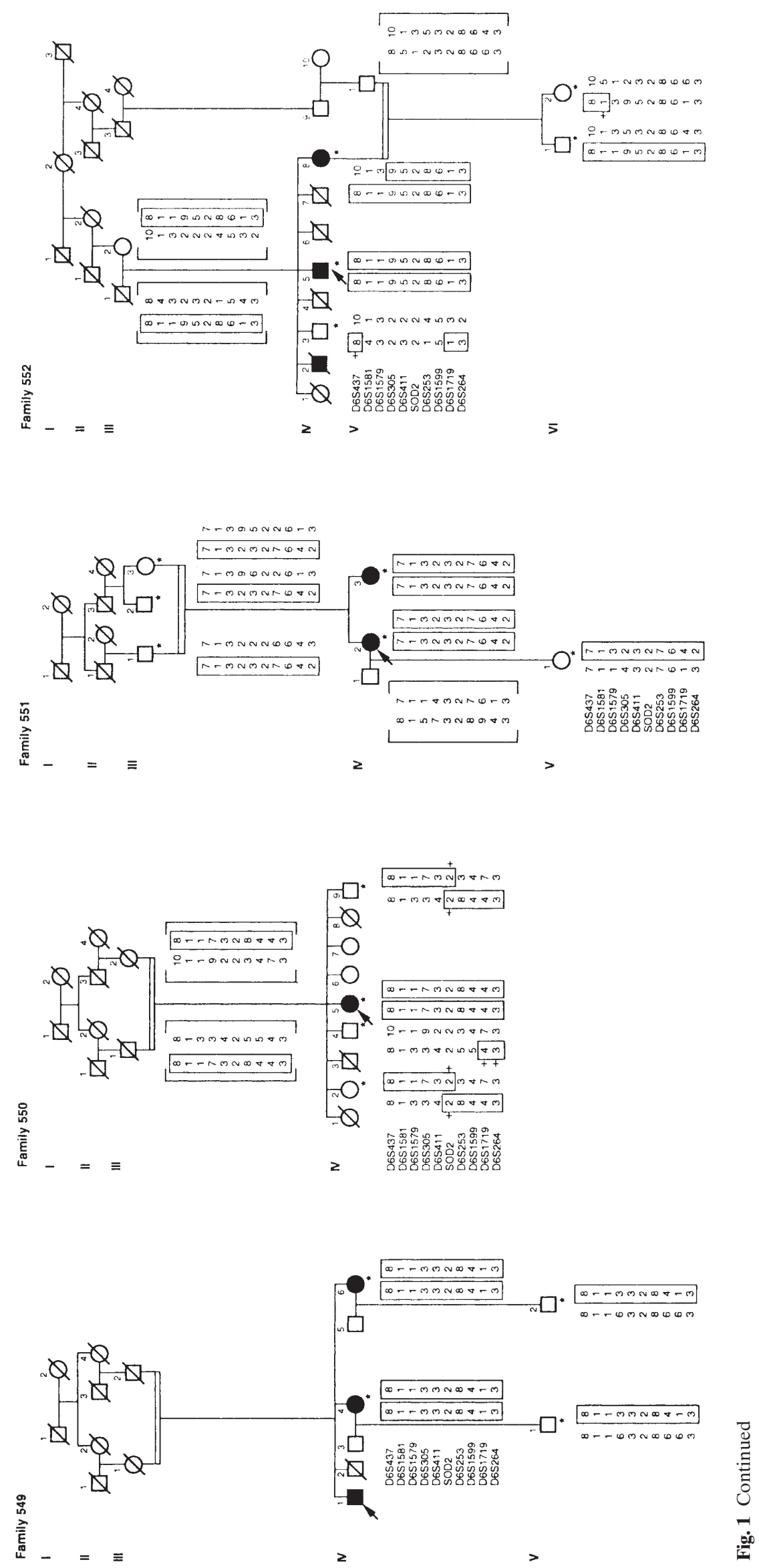

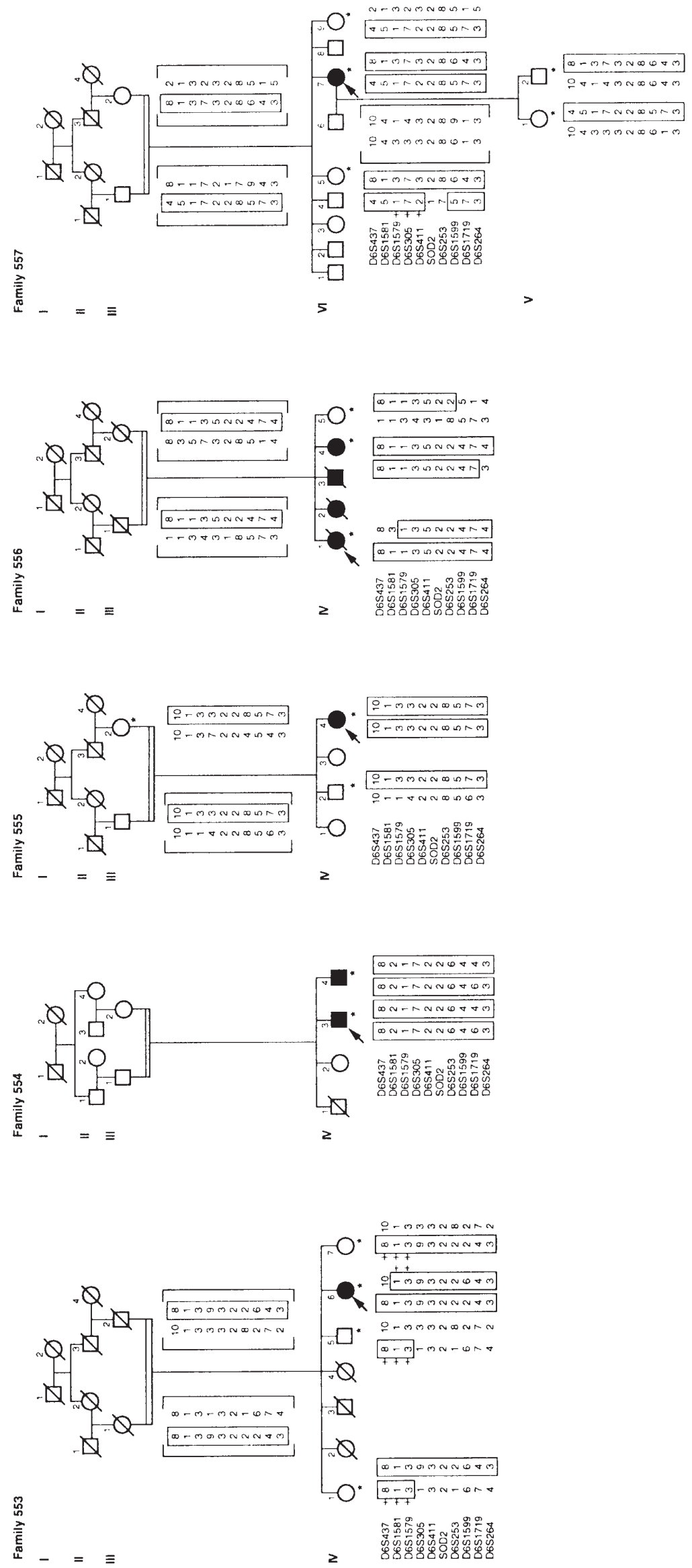
chromosome 6

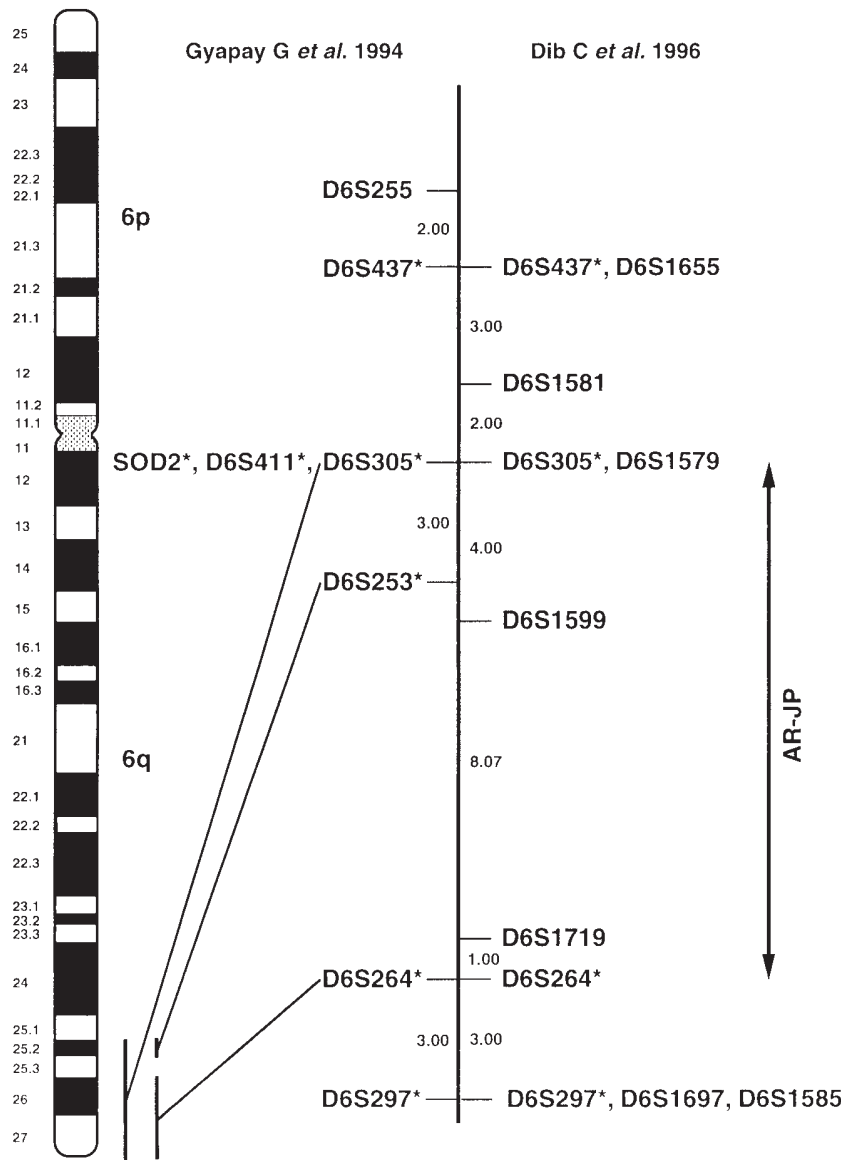

Fig. 2 Genetic maps of microsatellite markers used in the present study and the candidate region for the AR-JP gene. Genetic distances were derived from the Genethon map (Dib et al. 1996) and recently published data (Gyapay et al. 1994; Volz et al. 1994). Genetic distance was estimated using Haldane's map function. The candidate region for the AR-JP gene is indicated. D6S437, D6S1581, D6S1579, D6S305, D6S411, SOD2, D6S253, D6S1599, D6S1719 and D6S264 were used for linkage analysis, of which D6S437, D6S305, D6S411, SOD2, D6S253 and D6S264 (indicated by *) were used in our previous study (Matsumine et al. 1997)

disequilibrium analyses, the $2 \times n$ table $\chi^{2}$ test and the LRT $\chi^{2}$ test, were performed using the DISMULT program version 2.1 (Terwilliger 1995). The $\lambda$ values for evaluation of the degree of linkage disequilibrium were calculated using the DISLAMB program version 2.1 (Terwilliger 1995).

\section{Results}

Linkage analysis of AR-JP locus

Pairwise lod scores for the 10 microsatellite markers on the long arm of chromosome 6 are summarized in Table 1. The highest cumulative maximal lod score of 9.13 was obtained at D6S1579 $(\theta=0.05)$. Markers D6S1581, D6S305, D6S411, D6S253, D6S1599 and D6S1719 also showed
Table 1 Cumulative pairwise lod scores for AR-JP versus chromosome $6 \mathrm{q}$ markers

\begin{tabular}{|c|c|c|c|c|c|c|c|c|c|}
\hline \multirow[b]{2}{*}{ Locus } & \multicolumn{7}{|c|}{ Recombination Fraction } & \multirow[b]{2}{*}{$\mathrm{Zmax}$} & \multirow[b]{2}{*}{$\theta$} \\
\hline & 0.00 & 0.01 & 0.05 & 0.10 & 0.15 & 0.20 & 0.30 & & \\
\hline $6 \mathrm{~S} 437^{*}$ & & -1.88 & & 0.76 & 0.84 & 0.75 & 0.44 & 0.84 & 0.14 \\
\hline $6 \mathrm{~S} 1$ & $-\infty$ & 1.01 & & 3.87 & 3.61 & 3.11 & 1.93 & .87 & 0.10 \\
\hline 579 & $-\infty$ & & & & & & 3.63 & & 0.05 \\
\hline $305 *$ & 6.91 & 7.42 & 7.39 & 6.57 & 5.54 & 4.46 & 2.43 & 7.56 & 0.02 \\
\hline $11 *$ & 3.1 & 4.1 & 4.71 & 4.36 & 3.74 & 3.04 & 1.67 & 4.71 & 0.05 \\
\hline $\mathrm{OD} 2$ & 1.74 & 1.71 & 1.57 & 1.36 & 1.14 & 0.92 & 0.49 & 1.74 & 0.00 \\
\hline D6S253* & 7.28 & 7.64 & 7.47 & 6.61 & 5.59 & 4.55 & 2.60 & 7.71 & 0.02 \\
\hline D6S1599 & 4.47 & 7.58 & 7.84 & 7.06 & 6.04 & 4.94 & 2.79 & 7.96 & 0.03 \\
\hline D6S1719 & 1.42 & 3.80 & 4.85 & 4.57 & 3.93 & 3.20 & 1.78 & 4.85 & 0.06 \\
\hline D6S264* & $-\infty$ & 0.03 & 1.55 & 1.75 & 1.63 & 1.39 & 0.84 & 1.75 & 0.10 \\
\hline
\end{tabular}

AR-JP, autosomal recessive juvenile parkinsonism.

* Markers used in the previous study (Matsumine et al. 1997).

high lod scores of $\mathrm{Zmax}=3.87(\theta=0.10), \mathrm{Zmax}=7.56$ $(\theta=0.02), \quad Z \max =4.71 \quad(\theta=0.05), \quad Z \max =7.71$ $(\theta=0.02), \quad Z \max =7.96 \quad(\theta=0.03) \quad$ and $\quad Z \max =4.85$ $(\theta=0.06)$, respectively.

Obligate recombination events were detected at D6S1579 in one affected individual, IV-8 of family 552; and at D6S264 in three affected individuals: II-5 of family 101, V-1 of family 547 and IV-4 of family 556 (Fig. 1). These obligate recombination events restrict the AR-JP locus to a 13-cM region, the centromeric boundary of which is at D6S1579 and the telomeric boundary at D6S264. Although an unaffected individual (II-4, family 455) (Fig. 1) had haplotypes identical to those of the two affected siblings, she is 6 years old and still at risk for developing AR-JP in her later life.

Pairwise linkage analysis and recombination analysis suggested that the AR-JP gene is located in the region between D6S1579 and D6S264. The five markers (D6S1581, D6S1579, D6S1599, D6S1719 and D6S264) covering this region were selected from the linkage map (Dib et al. 1996) for multipoint linkage analysis. Multipoint linkage analysis revealed the highest cumulative maximal multipoint lod score of 12.4 at the locus $3 \mathrm{cM}$ telomeric to D6S1599. According to the Zmax-1 method (Conneally et al. 1985), the most likely location of the causative gene of AR-JP in the 14 families is estimated to be either within a 2.4-cM region centromeric to D6S1599 or within a 5.6-cM region telomeric to D6S1599 (Fig. 3). Multipoint likelihood calculations by homozygosity mapping were also performed with MAPMAKER/HOMOZ using seven markers (D6S437, D6S1581, D6S1579, D6S253, D6S1599, D6S1719 and D6S264) (Gupta et al. 1995), and revealed the highest cumulative maximal multipoint lod score of 14.7 at a locus $1 \mathrm{cM}$ telomeric to D6S1579 (Fig. 4).

Haplotype analysis and linkage disequilibrium at AR-JP locus

We constituted the haplotypes of these ten markers (D6S437, D6S1581，D6S1579, D6S305, D6S411, SOD2, 


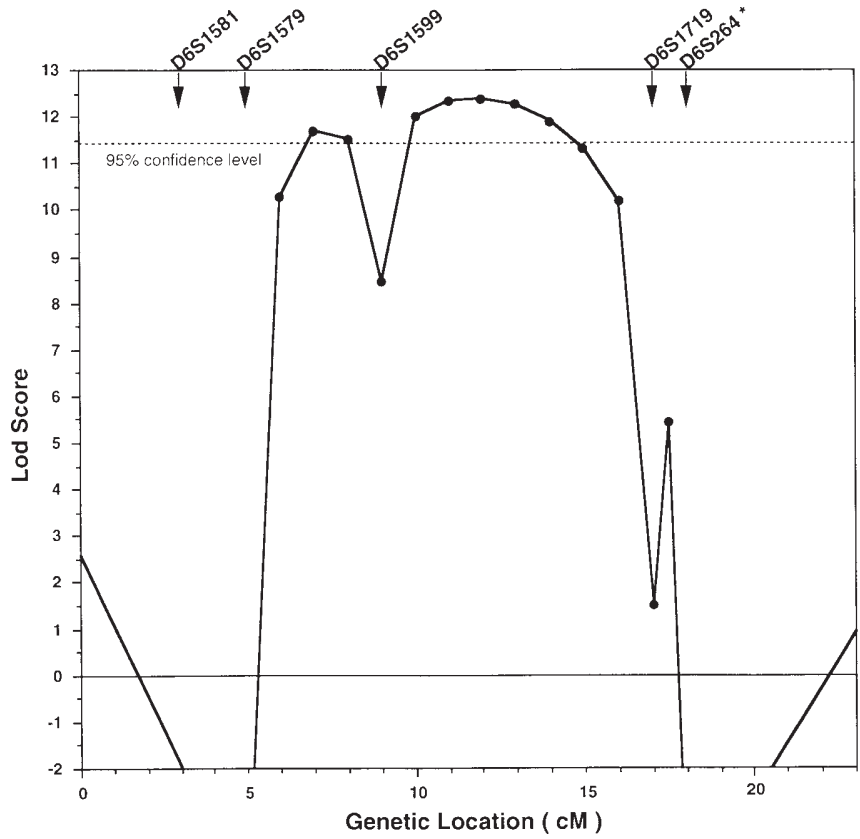

Fig. 3 Multipoint linkage analysis of the AR-JP locus on chromosome 6 . The highest cumulative maximal multipoint logarithm of differences (lod) score of 12.4 was obtained at the locus $3 \mathrm{cM}$ telomeric to D6S1599

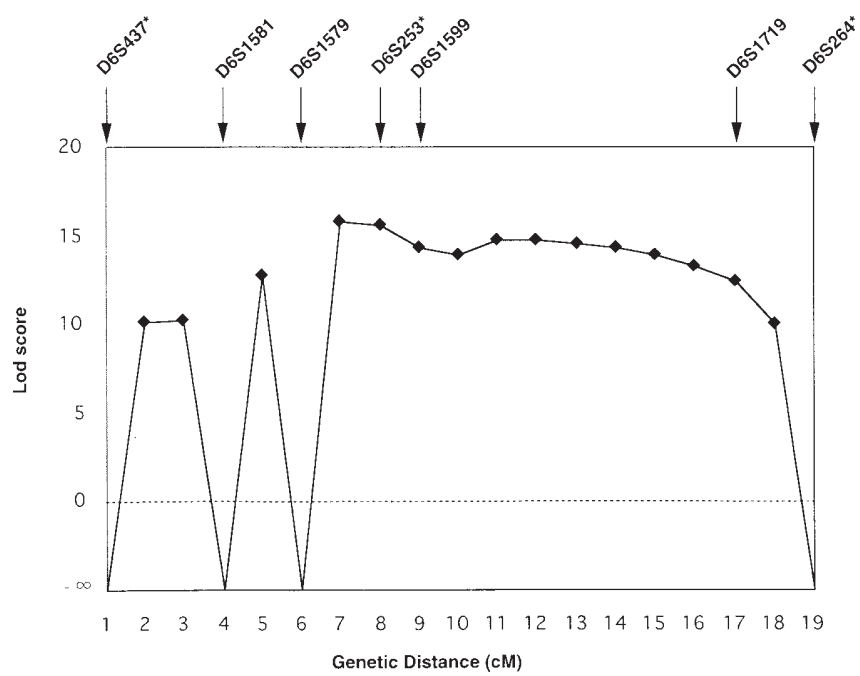

Fig. 4 Multipoint likelihood calculations by homozygosity mapping with the MAPMAKER/HOMOZ program using 7 markers. The highest cumulative multipoint lod score of 14.7 was obtained at the locus $1 \mathrm{cM}$ telomeric to D6S1579

D6S253, D6S1599, D6S1719 and D6S264) for each family (Fig. 1). Interestingly, families 549, 550 and 556 showed similar haplotypes of $8-1-1-3,8-1-1-7$ and 8-1-1-3 at D6S437-D6S1581-D6S1579-D6S305, and families 105, 548 and 557 also showed similar haplotypes of 6-1-3-7, 8-1-3-7 and 8-1-3-7 at D6S437-D6S1581-D6S1579-D6S305. In contrast, only one haplotype of 8-1-1-7 at D6S437-D6S1581D6S1579-D6S305 was observed (III-1, family 557) among the 28 haplotypes including the 15 deduced haplotypes in these pedigrees which are not cosegregating with the disease. This result further supports the localization of the AR-JP gene in the region close to D6S1579.

All affected individuals born to consanguineous parents exhibited homozygosity for at least some of the markers analyzed. Homozygosity in the affected individuals was observed for almost of all the markers in families 101, 105, 549, 550, 551, 552, 554, 555 and 556. Furthermore, homozygosity was observed at some of the markers in families 547, 548 and 557. Among the markers, D6S1579 is of interest since affected individuals born to consanguineous parents in 10 of the 11 families commonly showed homozygosity at D6S1579.

Table 2 shows the linkage disequilibrium data for the 14 Japanese AR-JP families. Two marker loci, D6S1579 and D6S1599, showed significant linkage disequilibria with the AR-JP locus. Allele 1 (159 bp) at the D6S1579 locus was detected in $9(40.9 \%)$ of the 22 founder chromosomes, while this allele was detected in only 2 of the 106 control chromosomes $\left[\chi^{2}(2 \times n\right.$ table $)=84.22 ; P<0.0001, \chi^{2}$ $($ LRT $)=20.66 ; P<0.0001, \lambda=0.40]$. Allele 6 (143 bp) at the D6S1599 locus was detected in 7 (31.8\%) of the 22 founder chromosomes, while this allele was detected in only 2 of the 106 control chromosomes $\left[\chi^{2}(2 \times n\right.$ table $)=63.37$; $P<0.0001, \chi^{2}($ LRT $\left.)=10.32 ; P<0.0001, \lambda=0.30\right]$. Similarly high cumulative multipoint likelihood-ratios of 46.4 and 46.7 were obtained at the loci $2.0 \mathrm{cM}$ telomeric to D6S1579 and $2.5 \mathrm{cM}$ telomeric to D6S1599, respectively (Fig. 5).

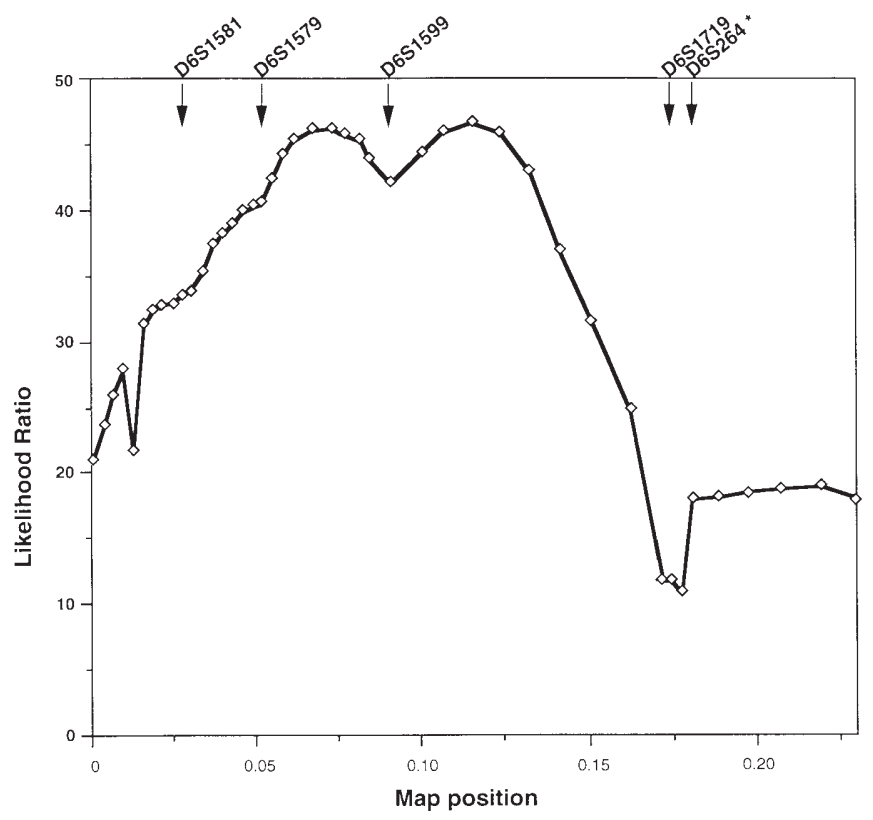

Fig. 5 Multipoint likelihood-ratio calculated using the DISMULT program. The genotypes at D6S1581, D6S1579, D6S1599, D6S1719 and D6S264 were used for calculation of the multipoint likelihoodratios. High cumulative multipoint likelihood-ratios of 46.4 and 46.7 were obtained at the loci $2.0 \mathrm{cM}$ telomeric to D6S1579 and $2.5 \mathrm{cM}$ telomeric to D6S1599, respectively 
Table 2 Linkage disequilibrium analysis

\begin{tabular}{|c|c|c|c|c|c|c|c|c|c|}
\hline \multirow[b]{2}{*}{ Locus } & \multirow[b]{2}{*}{ Allele } & \multirow[b]{2}{*}{ bp } & \multirow[b]{2}{*}{ AR-JP } & \multirow[b]{2}{*}{ Control } & \multicolumn{2}{|c|}{$2 \times n$ table } & \multicolumn{2}{|l|}{ LRT } & \multirow[b]{2}{*}{$\lambda$} \\
\hline & & & & & $\chi^{2}$ & $P$ & $\chi^{2}$ & $P$ & \\
\hline D6S437* & 1 & 165 & 0 & 1 & & & & & \\
\hline \multirow[t]{11}{*}{$161 / 163 * *$} & 2 & 161 & 0 & 5 & & & & & \\
\hline & 3 & 159 & 0 & 1 & & & & & \\
\hline & 4 & 157 & 1 & 1 & & & & & \\
\hline & 5 & 153 & 0 & 1 & & & & & \\
\hline & 6 & 151 & 1 & 1 & & & & & \\
\hline & 7 & 149 & 1 & 4 & & & & & \\
\hline & 8 & 133 & 11 & 56 & & & & & \\
\hline & 9 & 131 & 1 & 2 & & & & & \\
\hline & 10 & 128 & 7 & 53 & & & & & \\
\hline & 11 & others & 0 & 5 & & & & & \\
\hline & total & & 22 & 130 & 7.85 & 0.35 & 0 & 0.5 & 0 \\
\hline \multirow{7}{*}{$\begin{array}{l}\text { D6S1581 } \\
219 / 219^{* * *}\end{array}$} & 1 & 227 & 16 & 77 & & & & & \\
\hline & 2 & 225 & 2 & - & & & & & \\
\hline & 3 & 223 & 2 & 4 & & & & & \\
\hline & 4 & 219 & 0 & 8 & & & & & \\
\hline & 5 & 215 & 2 & 13 & & & & & \\
\hline & 6 & others & 0 & 3 & & & & & \\
\hline & total & & 22 & 106 & 8.70 & 0.12 & 0 & 0.49 & 0.01 \\
\hline D6S1579 & 1 & 159 & 9 & 2 & & & & & \\
\hline \multirow{6}{*}{ 149/181* } & 2 & 157 & 3 & 29 & & & & & \\
\hline & 3 & 155 & 9 & 1 & & & & & \\
\hline & 4 & 153 & 0 & 1 & & & & & \\
\hline & 5 & 147 & 1 & 69 & & & & & \\
\hline & 6 & others & 0 & 6 & & & & & \\
\hline & total & & 22 & 108 & 34.22 & $<0.0001$ & 20.56 & $<0.0001$ & 0.4 \\
\hline D6S303* & 1 & 232 & 0 & 3 & & & & & \\
\hline \multirow{10}{*}{$220 / 228 * *$} & 2 & 230 & 1 & 18 & & & & & \\
\hline & 3 & 228 & 5 & 20 & & & & & \\
\hline & 4 & 226 & 2 & 8 & & & & & \\
\hline & 5 & 224 & 1 & 6 & & & & & \\
\hline & 6 & 222 & 0 & 3 & & & & & \\
\hline & 7 & 220 & 6 & 37 & & & & & \\
\hline & 8 & 208 & 0 & 1 & & & & & \\
\hline & 9 & 206 & 7 & 28 & & & & & \\
\hline & 10 & others & 0 & 8 & & & & & \\
\hline & total & & 22 & 132 & 5.63 & 0.69 & 0 & 0.5 & 0 \\
\hline D6S411* & 1 & 161 & 0 & 3 & & & & & \\
\hline \multirow[t]{6}{*}{$157 / 159 * *$} & 2 & 159 & 7 & 29 & & & & & \\
\hline & 3 & 157 & 8 & 83 & & & & & \\
\hline & 4 & 153 & 0 & 5 & & & & & \\
\hline & 5 & 151 & 5 & 7 & & & & & \\
\hline & 6 & 143 & 1 & 1 & & & & & \\
\hline & total & & 22 & 128 & 12.77 & 0.03 & 0.67 & 0.21 & 0.15 \\
\hline SOD2* & 1 & Ala & 2 & 28 & & & & & \\
\hline \multirow[t]{2}{*}{$\mathrm{Val} / \mathrm{Val} * *$} & 2 & Val & 20 & 220 & & & & & \\
\hline & total & & 22 & 248 & 0.1 & 0.75 & 0 & 0.5 & 0 \\
\hline D6S253* & 1 & 269 & 1 & 5 & & & & & \\
\hline \multirow[t]{9}{*}{$271 / 271 * *$} & 2 & 287 & 5 & 13 & & & & & \\
\hline & 3 & 265 & 0 & 12 & & & & & \\
\hline & 4 & 283 & 4 & 15 & & & & & \\
\hline & 5 & 277 & 0 & 1 & & & & & \\
\hline & 6 & 275 & 1 & 1 & & & & & \\
\hline & 7 & 273 & 2 & 9 & & & & & \\
\hline & 8 & 271 & 9 & 70 & & & & & \\
\hline & 9 & others & 0 & 2 & & & & & \\
\hline & total & & 22 & 126 & 8.47 & 0.29 & 0 & 0.5 & 0 \\
\hline
\end{tabular}


Table 2 Continued

\begin{tabular}{|c|c|c|c|c|c|c|c|c|c|}
\hline \multirow[b]{2}{*}{ Locus } & \multirow[b]{2}{*}{ Allele } & \multirow[b]{2}{*}{$\mathrm{bp}$} & \multirow[b]{2}{*}{ AR-JP } & \multirow[b]{2}{*}{ Control } & \multicolumn{2}{|c|}{$2 \times n$ table } & \multicolumn{2}{|l|}{ LRT } & \multirow[b]{2}{*}{$\lambda$} \\
\hline & & & & & $\chi^{2}$ & $P$ & $\chi^{2}$ & $P$ & \\
\hline D6S1599 & 1 & 157 & 1 & 1 & & & & & \\
\hline \multirow[t]{11}{*}{$131 / 133^{* *}$} & 2 & 155 & 3 & 1 & & & & & \\
\hline & 3 & 153 & 1 & 3 & & & & & \\
\hline & 4 & 151 & 5 & 5 & & & & & \\
\hline & 5 & 149 & 5 & 7 & & & & & \\
\hline & 6 & 143 & 7 & 2 & & & & & \\
\hline & 7 & 137 & 0 & 3 & & & & & \\
\hline & 8 & 135 & 0 & 1 & & & & & \\
\hline & 9 & 133 & 0 & 23 & & & & & \\
\hline & 10 & 131 & 0 & 26 & & & & & \\
\hline & 11 & others & 0 & 33 & & & & & \\
\hline & total & & 22 & 106 & 63.37 & $<0.0001$ & 10.32 & $<0.0001$ & 0.3 \\
\hline D6S1719 & 1 & 184 & 7 & 24 & & & & & \\
\hline \multirow[t]{8}{*}{$178 / 178 * *$} & 2 & 182 & 0 & 2 & & & & & \\
\hline & 3 & 180 & 0 & 7 & & & & & \\
\hline & 4 & 178 & 6 & 33 & & & & & \\
\hline & 5 & 176 & 0 & 7 & & & & & \\
\hline & 6 & 174 & 2 & 8 & & & & & \\
\hline & 7 & 180 & 7 & 1 & & & & & \\
\hline & 8 & others & 0 & 24 & & & & & \\
\hline & total & & 22 & 106 & 36.87 & $<0.0001$ & 12.54 & 0.0002 & 0.31 \\
\hline D6S264* & 1 & 128 & 1 & 1 & & & & & \\
\hline \multirow[t]{6}{*}{$114 / 116^{* *}$} & 2 & 118 & 2 & 9 & & & & & \\
\hline & 3 & 116 & 16 & 105 & & & & & \\
\hline & 4 & 114 & 3 & 3 & & & & & \\
\hline & 5 & 112 & 0 & 2 & & & & & \\
\hline & 6 & others & 0 & 8 & & & & & \\
\hline & total & & 22 & 128 & 10.01 & 0.07 & 0 & 0.48 & 0.02 \\
\hline
\end{tabular}

LRT, likelihood-ratio test; bp, base pairs.

* Markers used in the previous study (Matsumine et al. 1997).

** Genotypes of the genomic DNA (CEPH 134702) which were used as a size reference.

\section{Discussion}

We previously mapped the AR-JP gene to a 17-cM region between D6S437 and D6S264 on chromosome 6q25.2-27 (Matsumine et al. 1997). In this study, the highest cumulative multipoint lod score of 12.4 was obtained at a region $3 \mathrm{cM}$ telomeric to D6S1599. Obligate recombination events were detected at D6S1579 in one affected individual, IV-8 of family 552, and at D6S264 in three affected individuals: II-5 of family $101, \mathrm{~V}-1$ of family 547 and IV-4 of family 556 (Fig. 1). These recombination events locate the AR-JP gene to a 13-cM region between D6S1579 as the centromeric boundary and D6S264 as the telomeric boundary.

In our previous study, homozygosity was detected in only 8 of the 11 families in which consanguineous marriages had occurred. In families 547, 548 and 557, homozygous segregation of the marker alleles was not detected in spite of the occurrence of consanguineous marriage (Matsumine et al. 1997). Interestingly, however, homozygosity was observed at D6S1579 in families 547 and 548. Since D6S1579 is a polymorphic marker with a \%heterozygosity of $51 \%$ in normal Japanese individuals in this study, the homozygosity at D6S1579 in affected individuals born to consanguineous parents in 10 of the 11 families, including families 547 and 548 , raises the possibility that the gene for AR-JP is located close to D6S1579. Consistent with this observation, multipoint likelihood calculations by homozygosity mapping performed with MAPMAKER/HOMOZ (Gupta et al. 1995) resulted in the highest cumulative maximal multipoint lod score of 14.7 at a very close distance of $1 \mathrm{cM}$ telomeric to D6S1579 (Fig. 4).

As a result of the haplotype analysis, similar haplotypes, 8-1-1-3 and 8-1-1-7 at D6S437-D6S1581-D6S1579-D6S305, and 6-1-3-7 and 8-1-3-7 at D6S437-D6S1581-D6S1579D6S305, were detected. Furthermore, the highest $\chi^{2}(2 \times n$ table and LRT) and $\lambda$ values were obtained at D6S1579 (Table 2), indicating that D6S1579 is in strong linkage disequilibrium with the AR-JP locus. Taken together, these results indicate that the most likely location of the AR-JP gene is in the region close to D6S1579. Another region flanking D6S1599 is also a region of interest, since the next highest $\chi^{2}(2 \times n$ table and LRT $)$ and $\lambda$ values were obtained at D6S1599 (Table 2).

Taken together, these results suggest that a candidate region for the AR-JP gene is most likely to be the area near the 4-cM region encompassing D6S1579 and D6S1599. To define precisely the candidate region for the AR-JP locus 
and eventually identify the AR-JP gene, identification of additional polymorphic markers and detailed analysis on recombination events and linkage disequilibrium using additional AR-JP families will be indispensable. Identification of the causative gene for AR-JP, in addition to the recently identified gene for autosomal dominant PD, the $\alpha$-synuclein gene (Polymeropoulos et al. 1997), will facilitate our understanding of the pathogenesis of PD.

Acknowledgments. We are grateful to all members of the families for their participation in this study. It is a pleasure to acknowledge the contribution to the present work by Drs. T. Kobayashi, H. Mori and T. Kondo (Department of Neurology, Juntendo University School of Medicine), M. Yokochi (Department of Neurology, Tokyo Metropolitan Ebara Hospital), Y. Mizutani (Department of Clinical Pathology, Tokyo Metropolitan Matsuzawa Hospital), Y. Yamamura (Institute of Health Science, Hiroshima University School of Medicine), S. Nakamura (The Third Department of Internal Medicine, Hiroshima University School of Medicine) and S. Kuzuhara (Department of Neurology, Mie University School of Medicine). We thank John Powell and Jim Tomlin of the Division of Computer Research and Technology at NIH for assistance with the SP2 computer. This study was supported in part by a grant from the Research for the Future Program of the Japan Society for Promotion of Science (JSPS-RFTF 96L00103); special coordination funds from the Japanese Science and Technology Agency; a grant for Surveys and Research on Specific Diseases, from the Ministry of Health and Welfare, Japan; a grant for scientific research on Priority Areas, Ministry of Education, Science and Culture, Japan; a Center of Excellence grant from the National Parkinson Foundation, Miami; a grant from the Uehara Memorial Foundation; and a grant from the Kato Memorial Trust for Nanbyo Research.

\section{References}

Amza C, Cox AL, Dwarkadas S, Keleher P, Lu HH, Rajamony R, Yu WM, Zwaenepoel W (1996) TreadMarks shared memory computing on networks of workstations. IEEE Comput 29:18-28

Conneally PM, Edwards JH, Kidd KK, Lalouel JM, Morton NE, Ott J, White R (1985) Report of the committee on methods of linkage analysis and reporting. Cytogenet Cell Genet 40:356-359

Cottingham RW, Idury RM, Schäffer AA (1993) Faster sequential genetic linkage computations. Am J Hum Genet 53:252-263

de Rijk MC, Breteler MM, Graveland GA, Ott A, Grobbee DE, van der Meche FG, Hofman A (1995) Prevalence of Parkinson's disease in the elderly: the Rotterdam Study. Neurology 45:21432146

Dib C, Faure S, Fizames C, Samson D, Drouot N, Vignal A, Millasseau P, Marc S, Hazan J, Seboun E, Lathrop M, Gyapay G, Morissette J, Weissenbach J (1996) A comprehensive genetic map of the human genome based on 5264 microsatellites. Nature 380:152-154

Goelz SE, Hamilton SR, Vogelstein B (1985) Purification of DNA from formaldehyde fixed and paraffin embedded human tissue. Biochem Biophys Res Commun 130:118-126

Gupta SK, Schäffer AA, Cox AL, Dwarkadas S, Zwaenepoel W (1995) Integrating parallelization strategies for linkage analysis. Comput Biomed Res 28:116-139
Gyapay G, Morissette J, Vignal A, Dib C, Fizames C, Millasseau P, Marc S, Bernardi G, Lathrop M, Weissenbach J (1994) The 1993-94 Genethon human genetic linkage map. Nat Genet 7:246-339

Ishikawa A, Tsuji S (1996) Clinical analysis of 17 patients in 12 Japanese families with autosomal recessive type juvenile parkinsonism. Neurology 47:160-166

Kondo T, Sugita H, Mizutani H, Mizuno Y (1990) Tyrosine hydroxylase activity in the nigro-striatal region in patients with juvenile Parkinsonism. Mov Disord (Suppl 5):29

Kruglyak L, Daly MJ, Lander ES (1995) Rapid multipoint linkage analysis of recessive traits in nuclear families, including homozygosity mapping. Am J Hum Genet 56:519-527

Lathrop GM, Lalouel JM (1985) Easy calculation of LOD scores and genetic risks on small computers. Am J Hum Genet 36:460-465

Lathrop GM, Lalouel JM, Julier C, Ott J (1985) Multilocus linkage analysis in humans: detection of linkage and estimation of recombination. Am J Hum Genet 37:482-498

Matsumine H, Saito M, Matsubayashi SS, Tanaka H, Ishikawa A, Hattori NY, Yokochi M, Kobayashi T, Igarashi S, Takano H, Sanpei K, Koike R, Mori H, Kondo T, Mizutani Y, Schäffer AA, Yamamura Y, Nakamura S, Kuzuhara S, Tsuji S, Mizuno Y (1997) Localization of a gene for autosomal recessive form of juvenile parkinsonism (AR-JP) to chromosome 6q25.2-27. Am J Hum Genet 60:588-596

Mizutani Y, Kondo T, Yokochi M (1993) Juvenile parkinsonism: Neuropathological findings of 9 cases (in Japanese). Gendaiiryou (Tokyo) 25:11-17

Polymeropoulos MH, Lavedan C, Leroy E, Ide SE, Dehejia A, Dutra A, Pike B, Root H, Rubenstein J, Boyer R, Stenroos ES, Chandrasekharappa S, Athanassiadou A, Papapetropoulos T, Johnson WG, Lazzarini AM, Duvoisin RC, Di Iorio G, Golbe LI, Nussbaum RL (1997) Mutation in the a-synuclein gene identified in families with Parkinson's disease. Science 276:2045-2047

Saito M, Tanaka H, Ishikawa A, Tsuji S (1995) Linkage analysis of autosomal recessive juvenile parkinsonism to GTP cyclohydrolase 1 gene locus on chromosome 14. Am J Hum Genet 57S:A326

Sambrook J, Fritsch EF, Maniatis T (1989) Molecular cloning: a laboratory manual, 2nd edn. Cold Spring Harbor Press, Cold Spring Harbor, NY

Schäffer AA, Gupta SK, Shriram K, Cottingham RW Jr (1994) Avoiding recomputation in linkage analysis. Hum Hered 44:225-237

Takahashi H, Ohama E, Suzuki S, Horikawa Y, Ishikawa A, Morita T, Tsuji S, Ikuta F (1994) Familial juvenile parkinsonism: clinical and pathologic study in a family. Neurology 44:437-441

Takubo H, Kondo T, Mori H, Miyake T, Suda K, Yokochi M, Imai H, Mizuno Y (1996) A 62-year-old man with familial parkinsonism with the onset at 24 years of the age (clinical conference) No To Shinkei 48:587-597

Tanaka H, Ishikawa A, Ginns EI, Miyatake T, Tsuji S (1987) Linkage analysis of juvenile parkinsonism to tyrosine hydroxylase gene locus on chromosome 11. Neurology 41:455-460

Terwilliger JD (1995) A powerful likelihood method for the analysis of linkage disequilibrium between trait loci and one or more polymorphic marker loci. Am J Hum Genet 56:777-787

Volz A, Boyle JM, Cann HM, Cottingham RW, Orr HT, Ziegler A (1994) Report of the second international workshop on human chromosome 6. Genomics 21:464-472

Weber JL, May PE (1989) Abundant class of human DNA polymorphisms which can be typed using the polymerase chain reaction. Am J Hum Genet 44:388-396

Yamamura Y, Sobue I, Ando K, Iida M, Yanagi T (1973) Paralysis agitans of early onset with marked diurnal fluctuation of symptoms. Neurology 23:239-244 